\title{
ESCOLA ESPECIAL, ESCOLA INCLUSIVA: O ESTATUTO DA NORMALIDADE SOB A ÓTICA DAS REPRESENTAÇÕES*
}

Rita Francis Gonzalez y Rodrigues Branco**

\section{RESUMO}

Este texto pretende ser polêmico e transformador. Seu objetivo não é outro senão incomodar. Tento aqui refletir sobre algumas questões a respeito de representações sociais e educação, saúde e normalidade, escola especial e inclusiva. Desses pensamentos, uma análise inquietante surgiu - a construção social do estatuto da normalidade. Decidi elaborar este artigo que, sei, é angustiante para todos nós que nos acreditamos "normais". A inquietação que pretendo remeter a cada leitor não deixa de ser uma sedução para que possamos, quem sabe, juntos, construir uma nova realidade social.

Palavras-chave: Escola inclusiva. Escola especial. Normalidade. Representações sociais.

\section{REFLETINDO SOBRE O TEMA}

A educação especial e a escola inclusiva, embora tenham uma legislação nacional e internacional que as respaldem (Monte; Siqueira; MirAndA, 2001), precisam ser refletidas sob várias óticas para que possam, realmente, se efetivar. A política de inclusão tem sua matriz na carta de Jomtien (Plano Decenal de Educação para Todos, 1990), no Plano Nacional de Educação para Todos (MArchezAN, 2000) e na Declaração de Salamanca (A Declaração de Salamanca, 2005), sendo determinada pelas Diretrizes Nacionais de Educação Especial na Educação Básica de 2001 (BRAsIL, 2001).

\footnotetext{
* Artigo recebido em 17/5/2007 e aprovado em 1/8/2007.

** Professora do Departamento de Medicina da Universidade Católica de Goiás. E-mail: rfbranco@terra.com.br
} 
O conceito de inclusão aponta para a necessidade de aprofundar o debate sobre a diversidade. Isto implicaria em buscar compreender a heterogenicidade, as diferenças individuais e coletivas, as especificidades do humano e, sobretudo, as diferentes situações vividas na realidade social e no cotidiano escolar. (BRAsIL, s.d., p. 11)

Embora o verbo "incluir", do latim includere, signifique "conter", "compreender", "fazer parte" ou "participar" (RAmos, 2003), ao referirse à inclusão escolar, o conceito se reduz aos que apresentam "necessidades especiais de aprendizagem". Assim, pensar em inclusão escolar pressupõe que exista uma escola de crianças "normais", com desenvolvimento "normal" e com um potencial de aprendizagem considerado "normal", onde poderiam ser incluídos os "diferentes". Afinal, quem inclui, inclui alguém (que está excluído - e assim o está, por ser diferente) em algum lugar, que é considerado o lócus da normalidade (aquele que contempla a média considerada normal).

Esse conceito está posto claramente no discurso introdutório, escrito pelo então ministro da Educação, professor Paulo Renato Souza, na apresentação das Diretrizes Nacionais para a Educação Especial na Educação Básica:

Em todo o mundo, por muito tempo, o diferente foi colocado à margem da educação: o aluno com deficiência, particularmente, era atendido apenas em separado ou então excluído do processo educativo, com base em padrões de normalidade. [...] A adoção do conceito de necessidades educacionais especiais e do horizonte da educação inclusiva implica mudanças significativas. Em vez de se pensar no aluno como a origem de um problema, exigindo-se dele um ajustamento a padrões de normalidade para aprender com os demais, coloca-se para os sistemas de ensino e para as escolas o desafio de construir, coletivamente, as condições para atender bem à diversidade de seus alunos. (BrasiL, 2001) ${ }^{1}$

Portanto, pensar a inclusão escolar nos remete à reflexão sobre a escola que temos, ou pensamos ter, vista como um local de plena normalidade e que, em face da legislação atual, abre suas portas para as crianças que têm necessidades especiais de aprendizagem, inclusive, estabelecendo uma proposta de construção de um projeto pedagógico que, a partir de então, respeitará as necessidades específicas de cada 
aluno. Pensar a inclusão remete-nos, pois, à discussão da própria normalidade enquanto instituição social à que se deve ser incluído.

\section{BUSCANDO O REFERENCIAL TEÓRICO}

Pensar a normalidade não é um exercício fácil, visto que nos leva à necessidade de distanciamento de conceitos profundamente arraigados em nosso cotidiano. Pensar a normalidade é, antes de tudo, possibilitar a desconstrução do normal e propiciar a ressignificação do Ser em sua essência: nem iguais (normais) nem, tampouco, diferentes enquanto percebidos como anormais (fora dos padrões estabelecidos como normalidade). E, para pensar a normalidade, necessário se faz escolher os óculos e as lentes teóricas que propiciarão um novo olhar-para.

Assim, a teoria das representações é uma das possibilidades de lentes para que a visão possa ser ampliada no sentido de melhor discutir o conceito de normal. A teoria das representações pode auxiliar-nos nesta reflexão e permitir-nos pensar sobre como e por que a escola passou a ser entendida como lócus da normalidade, visto que

Uma representação social é a organização de imagens e linguagem, porque ela realça e simboliza atos e situações que nos são ou se nos tornam comuns. [...] A analogia com uma fotografia captada e alojada no cérebro é fascinante; a delicadeza de uma representação é, por conseguinte, comparada ao grau de definição e nitidez ótica de uma imagem. [...] Em poucas palavras, a representação social é uma modalidade de conhecimento particular que tem por função a elaboração de comportamentos e a comunicação entre indivíduos. (Moscovici, 1978, p. 25-26)

A pergunta que se faz é se há pertinência em considerar a normalidade como objeto possível de representação social. Procurando responder a esta relevante questão (até por que se não esclarecido este ponto, não há como prosseguir nessa reflexão proposta), convido Sá (1998, p. 45) para dizer-nos como se identificam os fenômenos de representação social: "para gerar representações sociais, o objeto deveria ter suficiente 'relevância cultural' ou 'espessura social"'. Ainda assim, persiste a dúvida se o "normal" (ou a normalidade) é de relevância cultural ou de espessura social. Permanecendo a dúvida sobre a pertinência ou 
não do normal como objeto possível de uma análise através das representações sociais, Sá esclarece mais uma vez:

Inicialmente, devemos reconhecer que uma dificuldade para a identificação prévia dos fenômenos de representação social é dada pela possibilidade de um determinado objeto não ser socialmente representado por um dado grupo e que, não obstante, seus membros falem sobre tal objeto. Podem fazê-lo ao emitirem uma opinião isolada ou uma atitude favorável ou desfavorável sobre o objeto, talvez no decorrer de uma conversa sobre outros assuntos. $\left(1998\right.$, p. 48) ${ }^{2}$

O "normal" como conceito estabelecido é falado por toda a sociedade - seja a favor de um estatuto de normalidade ou não. $\mathrm{O}$ "normal" como possibilidade a ser alcançada é referido não só pelas pessoas em seu cotidiano, mas também na mídia como discurso hegemônico da sociedade ocidental. Daí se concluir sobre a pertinência de abordagem deste tema como objeto de uma análise através das representações sociais.

Partindo desse referencial teórico, tentarei compreender, ou pelo mesmo questionar, o que se considera normal dentro de uma escola, para que possamos, todos, pensar sobre o que significa uma escola inclusiva. Nesta linha de pensamento, o olhar se distancia do que se pensa ser uma criança normal e procura-se ressignificar o conceito de normalidade e necessidades especiais, repensando cada sujeito com seus limites e suas possibilidades.

\section{A REPRESENTAÇÃO SOCIAL DA NORMALIDADE}

De acordo com o Novo Dicionário Aurélio da Língua Portuguesa, a palavra "normal" significa "que é segundo a norma, habitual, natural;" apresentando, como exemplos, citações da Física e da Química "aceleração normal da gravidade, condições normais de temperatura e pressão, curvatura normal" - dentre outras (FERREIRA, 1975, p. 977-978). Quanto ao vernáculo "normalidade", o referido dicionário diz ser referente à "normal", na norma. Assim, vê-se claramente a influência dos conceitos da Física e da Química na origem desta palavra. Tomando a Curva de Gauss como objeto de análise, entende-se como normal (a norma) o que se encontra dentro da referida curva, o que, em última 
análise representa a maioria estatística. A Curva de Gauss vem, ao longo dos anos, firmando-se como o paradigma da pesquisa quantitativa, sendo, pois, uma referência estatística, dando respaldo ao conhecimento científico. Como um conceito matemático relacionado à estatística, à Física e à Química, a normalidade (normal, norma) introduziu-se no cotidiano social, permeando conhecimentos nas áreas de saúde e educação.

Saúde não é sinônimo de normalidade. Seu conceito, segundo a Organização Mundial da Saúde (OMS), "é um estado de completo bemestar físico, mental e social", não significando, pois, o normal ou a ausência de doenças ou de invalidez (PоRTO, 2001). Ao contrário, o conceito de saúde nessa perspectiva pretende, não só, englobar fatores biológicos, sociais e psicológicos em sua gênese, mas, sobretudo, pretende respeitar a diversidade, compreendendo que, mesmo fora da "normalidade" estatística, uma pessoa pode ser considerada saudável, desde que esteja em um estado de equilíbrio biopsicossocial.

Visto que o conceito de saúde não se relaciona com o conceito de normalidade, necessário se faz refletir sobre como o "normal" passou a ser compreendido pela sociedade como paradigma de saúde. Ora, tomando as palavras de Berger e Luckmann:

O processo de tornar-se homem efetua-se na correlação com o ambiente. [...] O ser humano em desenvolvimento não somente se correlaciona com um ambiente natural particular, mas também com uma ordem cultural e social específica, que é mediatizada para ele pelos outros significativos que o têm a seu cargo. Não apenas a sobrevivência da criança humana depende de certos dispositivos sociais, mas a direção de seu desenvolvimento orgânico é socialmente determinado. [...] A relação do homem com seu ambiente caracterizase pela abertura para o mundo. (BERGER; LUCKMANN, 1985, p. 70-71)

Pensando em como os diferentes passaram para o cenário da exclusão, há necessidade de resgatar os mais antigos relatos sobre tais questões. No passado, diante de um ambiente inóspito, a estratificação social colocava o homem na oposição de caçador e a mulher na posição de guardiã e mantenedora do clã. Pensando em como uma criança com alterações visuais, dificuldade locomotora ou com outra situação de diferença que possibilitasse alguma necessidade especial, seria um complicador, não só na perpetuação de tais papéis sociais, mas também 
nas constantes mobilizações das tribos nômades, pode-se concluir que não eram vistas como pessoas comuns, normais, e, portanto, poderiam ser segregadas, ocorrendo, assim, a socialização primária deste fenômeno SOcial (BERGER; LUCKMANN, 1985).

A Bíblia mostra como os judeus, em épocas remotas, ainda nômades, percebiam tais crianças deficientes. No Antigo Testamento, é repetidamente citado o fato de que os cegos e coxos assim o eram, devido aos pecados de seus pais. Jesus procurou desconstruir tal conceito revisto no Novo Testamento, porém, mesmo dentro do cristianismo, ao contrário de seus ensinamentos, o conceito de deficiência como castigo permaneceu. Caminhando na história,

A literatura da Roma Antiga relata que as crianças com deficiência, nascidas até o princípio da era cristã, eram afogadas por serem consideradas anormais e débeis. Na Grécia antiga, Platão relata no seu livro "A República" que as crianças mal constituídas ou deficientes eram sacrificadas ou escondidas pelo poder público. (BRASIL, s.d., p. 9)

Percebe-se que, ao longo dos anos, foram sendo criados conceitos e atitudes que culminaram com a exclusão das pessoas portadoras de alterações físicas e mentais, que as limitassem para o fazer social instituído, ocorrendo assim a socialização secundária (BERGER; LucKMANN, 1985). Ainda convidando Berger e Luckmann para esclarecerem a relação homem/norma social:

A ordem social existe unicamente como produto da atividade humana. [...] A inerente instabilidade do organismo humano obriga o homem a fornecer a si mesmo um ambiente estável para sua conduta. O próprio homem tem de especializar e dirigir seus impulsos. Estes fatos biológicos servem de premissas necessárias para a produção da ordem social. Em outras palavras, embora nenhuma ordem social existente possa ser derivada de dados biológicos, a necessidade da ordem social enquanto tal provém do equipamento biológico do homem. (BERGER; LuCKMANN, 1985, p. 76-77)

Assim sendo e sabendo que até o século XVIII a mortalidade infantil era muito alta, influenciando inclusive no próprio reconhecimento da infância enquanto tal, sobreviviam mais os que, biologicamente, estavam mais aptos ao enfrentamento de um ambiente social mais 
inóspito. Pensando que, estatisticamente, as pessoas cegas, com deficiência locomotora ou com transtornos mentais, não eram a maioria (embora sejam estatisticamente um montante significativo), compreendese que tenha sido construída uma ordem social mais voltada à maioria vista como normal. Desse modo, as ações dessa maioria foram, ao longo dos anos, tornando-se habituais e significativas para os sujeitos, de forma a possibilitar tipificações. O desenvolvimento científico que possibilitou a descoberta dos microorganismos acabou por levar a um fazer obsessivo dos higienistas, propiciando o desejo familiar (em especial das mães) de garantir filhos saudáveis (OliveIRA,1985). Assim, o normal (a maioria) se institucionalizou. De acordo com Berger e Luckmann, "a institucionalização ocorre sempre que há uma tipificação recíproca de ações habituais por tipos de atores" (1985, p. 79).

Entendido como o estatuto da normalidade foi construído a partir das representações sociais, resta agora entender como a escola tornouse lócus da normalidade.

\section{UMA ESCOLA PARA PESSOAS NORMAIS?!}

Embora sabendo, hoje, que a diversidade é uma característica do humano e que as pessoas não são absolutamente iguais, e, sobretudo, que não há realmente um padrão de normalidade baseado nos conceitos de saúde, a institucionalização do estatuto da normalidade é tão entranhado no fazer social, que nem se cogita discuti-lo. Ora, a escola, sendo uma instituição social, está, e sempre esteve, permeada por tal representação social do normal. Segundo Oliveira,

Para compreender aquilo que chamamos de escola em sua dimensão institucional, como um projeto político-ideológico-social, presa a um conjunto de ideais, será preciso admitir que, nos bastidores dessa definição, se escondem outros significados às vezes não tão transparentes. O primeiro passo é reconhecer a escola como fruto de uma construção humana que a legitimou com base no sonho de uma sociedade universal, perfeita e justa. (2002, p. 33-34)

A mesma autora faz referência à escola pós-feudal, quando surge uma nova ordem social (a burguesia). Nesse período, surge uma escola que se dispõe a formar o "homem para o mundo, um homem total e 
perfeito" (Oliveira, 2002, p. 34). Assim, as expressões "sociedade perfeita", "homem total e perfeito" são da ordem do imaginário e compatíveis com o estatuto da normalidade.

$\mathrm{O}$ advento da Física e o cientificismo que tomou conta da sociedade, no século XVIII, bem como os avanços da Medicina, sobretudo nas áreas da microbiologia e infectologia, acabaram corroborando a institucionalização do estatuto da normalidade. A Curva de Gauss demonstrou matematicamente que os "normais" eram a maioria. A crença de que a Matemática e a estatística dão veracidade à ciência não permitiu dúvidas quanto à normalidade instituída. Assim, a escola acabou colocando-se como representante desta ordem social:

Há uma forte ligação que se instala entre o movimento higienista e os interesse do Estado. Este se vê fortalecido por essa "normalização" da família e passa a pleitear essa meta, pois vislumbra, nessa ação educativa, a possibilidade de maior controle sobre os indivíduos. [...] As escolas, principalmente os internatos, representam um lugar oficial e legítimo para (re)formar as crianças, suprir a suposta deficiência da família e monopolizar o controle do Estado. (Oliveira, 1985, p. 33)

A escola passa, então, legitimamente, a ser o lócus da normalidade e seu projeto político não é outro senão formar pessoas capazes para o mundo do trabalho e para bem servir ao Estado. Os diferentes não têm, pois, espaço na escola dos "normais". Crianças diabéticas, cardiopatas, epilépticas, dislexas, com transtorno de hiperatividade, com transtornos mentais leves não são reconhecidas em suas diferenças. São recebidas e tratadas no âmbito escolar como se fossem normais. Os possíveis complicadores da aprendizagem ligados às doenças crônico-degenerativas (diabetes, cardiopatias, epilepsia, transtornos mentais leves, doenças reumatológicas, vitiligo etc.) são desconhecidos e desvalorizados. Crianças com miopia são vítimas do fracasso escolar, crianças sinistras (canhotas) são forçadas a escrever em carteiras construídas para os destros, asmáticos são forçados a ter o mesmo rendimento que os outros nas atividades físicas, crianças que se submetem a várias internações hospitalares acabam fora da escola, incluídas no âmbito do fracasso escolar. Todos são vistos como iguais e, sobretudo, como normais.

A escola inclusiva é de extrema importância e a sua completa efetivação é um exercício de cidadania. O que quero deixar como 
possibilidade de reflexão é que não existe realmente uma escola de normais que abre suas portas para as crianças com necessidades especiais, mas, sim, que existe uma escola que congrega em seu cenário crianças diferentes entre si, cada qual com seus limites e suas possibilidades, com suas necessidades especiais - umas mais do que as outras, mas todas com suas eficiências e suas deficiências, visto que o ser humano não é absolutamente normal.

Se cada um de nós - professores, médicos, psicólogos, psicopedagogos - pensar em como o estatuto da normalidade é um constructo a partir das representações sociais, poderemos, juntos, tentar construir novas representações e permitir que uma nova sociedade mais inclusiva, respeitadora da diversidade de cada Ser, possa vagarosamente ser (re)construída.

\section{ABSTRACT}

This text aims to be polemic and transforming. Its only objective is to disturb. It is a reflection on certain issues concerned with social representations and education, health and normality, special and inclusive schools. A disturbing analysis arose out of these questions: the social construction of the statute of normality. So, I decided to write this article, which I know is disturbing for all of us who consider ourselves 'normal'. The unease to which I intend to submit each reader, is actually a kind of inducement for all of us together to construct a new social reality.

Key Words: Inclusive school. Special school. Normality. Social representations.

\section{NOTAS}

1. Nota - os grifos em itálico foram feitos por mim para ressaltar a existência do conceito de normalidade.

2. Grifo do autor citado.

\section{REFERÊNCIAS}

A DECLARAÇÃO DE SALAMANCA: sobre princípios, política e prática em educação especial. Disponível em: <http://www.lerparaver.com/legislacao/ internacional_salamanca.html >. Acesso em: 21 jan. 2005

BERGER, P. L.; LUCKMANN, T. A construção social da realidade: tratado de sociologia do conhecimento. Tradução de Floriano de Souza Fernandes. 23. edição. Petrópolis, RJ: Vozes, 2003. 
BRASIL. MINISTÉRIO DA EDUCAÇÃO. Diretrizes Nacionais para a Educação Especial na Educação Básica. Brasília, DF: Secretaria de Educação Especial-MEC/SEESP, 2001.

BRASIL. MINISTÉRIO DA EDUCAÇÃO. Estratégias e Orientações Pedagógicas para a Educação de Crianças com Necessidades Educacionais Especiais. Introdução - Coleção Educação Infantil Tomo 1. Brasília, DF: Ministério da Educação/Secretaria de Educação Especial, s.d.

FERREIRA, A. B. H. Novo Dicionário Aurélio da Lingua Portuguesa. 1. ed. Rio de Janeiro: Nova Fronteira, 1975.

MARCHEZAN, N. (Relator). Plano Nacional de Educação. Brasília, DF: Centro de Documentação e Informação/Coordenação de Publicações/Câmara dos Deputados, 2000.

MONTE, F. R. F.; SIQUEIRA, I.; MIRANDA, J. R. (Orgs.). Direito à educação: necessidades educacionais especiais: subsídios para atuação do Ministério Público Brasileiro. Brasília, DF: MEC/SEESP, 2001.

MOSCOVICI, S. A representação social da psicanálise. Rio de Janeiro: Zahar Editores, 1978.

OLIVEIRA, L. C. F. Escola e família - Numa rede de (des)encontros: um estudo das representações de pais e professores. 1. ed. Taubaté, SP: Cabral Editora e Livraria Universitária, 2002.

PLANO DECENAL DE EDUCAÇÃO PARA TODOS. Declaração Mundial sobre Educação para Todos. Jomtien-Tailândia, 5 a 9 de março de 1990.

PORTO, C. C. (Org.) Semiologia médica. 4. ed. Rio de Janeiro: Guanabara Koogan, 2001.

RAMOS, B. Vamos incluir! Escola Promotora de Saúde. Manual da Sociedade Brasileira de Pediatria. 1. ed. Rio de Janeiro: SBP/Nestlé Nutrição, 2003.

SÁ, C. P. A construção do objeto de pesquisa em representações sociais. Rio de Janeiro: Editora da UERJ, 1998. 